\section{The effects of sports participation on internet addiction of high school students}

\section{Spora katılımın lise öğrencilerinin internet bağımlılığına etkisi}

\author{
Ali Aycan ${ }^{1}$ \\ Hanifi Üzüm ${ }^{2}$
}

\begin{abstract}
The purpose of this study was to investigate the effects of sport participation status on internet addiction of high school students. The sample group consisted of total 430 students (220 licensed student athletes and 210 non-athletes) from 10 different high schools in Bolu center. Research data were obtained by "Young Internet Addiction Test Short Form" (YIBTKF) which was adapted to Turkish by Kutlu Savc1, Demir ve Arslan (2016). Internal consistency of the scale was calculated as $\alpha=$ 0.93 in this study. The results of this study showed that a) internet addiction levels of male students were higher than female students, b) internet addiction levels of athlete students were lower than non-athlete students, c) academic success for athlete students were more positive effect in internet addiction and d) the negative effect of long-term usage a smart phone had less negative effect on internet addiction level of athlete students.
\end{abstract}

Keywords: Internet Addiction, High School Students, Sport.

(Extended English summary is at the end of this document)

\section{Özet}

$\mathrm{Bu}$ çalışmada, lise öğrencilerinin spora katılım durumlarının internet bağımlılıklarına etkisinin incelenmesi amaçlanmıştır. Bolu merkezindeki 10 farklı liseden toplam 430 öğrenci (220 lisanlı spor yapan ve 210 lisanslı olarak spor yapmayan) çalışmanın örneklem grubunu oluşmuştur. Çalışma verilerinin toplanmasında, Kutlu, Savcı, Demir ve Arslan (2016) tarafindan Türkçeye uyarlanan "Young İnternet Bağımlilı̆̆1 Testi Kisa Formu" (YİBT-KF) kullanılmıştır. Bu çalışma için ölçeğin Cronbach Alpha iç tutarlılık değerleri ise $\alpha=0.93$ olarak hesaplanmıştur. Araştırmada, a) spor yapan öğrencilerin internet bağımliliklarının yapmayanlardan daha düşük olduğu sonucuna ulaşılmıştr. b) erkek öğrencilerin internet bağımllitk düzeylerinin kadın öğrencilerden daha yüksek olduğu, c) spor yapanlarda yapmayanlara göre akademik başarının internet bağımlilığında daha etkili olduğu ve d) spor yapanlarda yapmayanlara göre cep telefonu kullanim yllnin internet bağımlilığına etkisinin daha az olduğu sonucuna ulaşılmıştır.

Anahtar Kelimeler: İnternet Bağımlllı̆̆ı, Lise Öğrencisi, Spor.

\footnotetext{
1 Doç. Dr. Bolu Abant İzzet Baysal Üniversitesi, Spor Bilimleri Fakültesi, aycan a1@,ibu.edu.tr (iD) Orcid ID: 0000-0002-4354-2526

2 Doç. Dr. Bolu Abant İzzet Baysal Üniversitesi, Spor Bilimleri Fakültesi, uzum h@ibu.edu.tr (iD) Orcid ID: 0000-0002-0555-266X
} 
Aycan, A. \& Üzüm, H. (2020). Spora katılımın lise öğrencilerinin internet bağımlilı̆̆ına etkisi. Journal of Human Sciences, 17(4), 1022-1033. doi:10.14687/jhs.v17i4.6051

\section{Giriş}

Birçok insan için günlük yaşamın önemli bir parçası olan internet, iletişim kurma, bilgi edinme, satın alma ve daha birçok etkinlik için kullanılmaktadır. Son yıllarda, yeni bir bağımlılık türü olarak internet bağımlılı̆̆1 sosyoloji, psikoloji ve iletişim başta olmak üzere farklı disiplinlerden araştırmacıların dikkatini çeken önemli bir çalışma alanı haline gelmiştir (Balcı ve Gülnar, 2009).

Dünyada ve ülkemizde son yıllarda ortaya çıkan hızlı sosyal, ekonomik ve teknolojik gelişim ve değişimlerin, internete erişimin yaygınlaşmasına, ucuzlamasına ve internet erişim araçlarına sahipliğin kolaylaşmasına neden olduğu söylenebilir. Günlük yaşamın her alnında, her yaştan ve her meslekten bireylerin farklı amaçlarla internet kullanımları her geçen gün gözle görülür biçimde artmaktadır. 2019 ylı Türkiye İstatistik Kurumu (TÜİK) verilerine göre, internet kullanımı son beş yılda \% 55,9'dan \% 75,3'e ve hanelerde internet erişimi ise \% 69,5'den \% 88,3'e yükselmiştir (TÜiK, 2019).

İnternet erişimi ve kullanımındaki bu artıştan lise çağındaki gençlerin nasibini almamış olması beklenemez. Bu durum, ülkemiz adına olumlu bir gelişme olarak görülmelidir. Çünkü bilgi çağ1 ya da dijital çağ olarak adlandırılan 21.yüzyılda internet ve internet aracillğıyla gerçekleştirilen faaliyetlerden uzak kalmak veya faydalanmamak söz konusu olamaz. Hayatımızın her alanında (eğitim, sağlık, ticaret, iletişim vb) internet kullanılarak gerçekleştirilen faaliyetlerin sayısı ve önemi hızla artmaktadır. Bu durum, aşırı, gereksiz ve zararlı internet kullanımını da beraberinde getirmekte ve özellikle teknolojiye daha hakim olan gençleri ve çocukları etkileyerek (Arısoy, 2009; Wang ve diğ., 2011) onların fiziksel, ruhsal ve sosyal problemlerle karşı karşıya kalmalarına neden olmaktadır (Çakır ve Sıngın, 2019; Dinç, 2015). Ancak, hayatımıza giren her yeni gelişmenin faydaları olduğu gibi zararlarının da olduğunun farkında olmamız ve özellikle gelişme dönemini henüz tamamlamamış gençleri ve çocukları her türlü zararlı etkilerden korumamız geleceğimiz açısından önem arz etmektedir.

\section{1. İnternet Bağımlılı̆̆1 Kavramı}

Goldberg (1996), İnternet Bağımlılı̆̆1 Bozukluğunu (IAD) tanımlamak için bir terim oluşturan ve İnternet bağımlıları için bir destek grubu kuran ilk kişidir. İnternet bağımlılı̆̆1 bozukluğunu tanımlamada madde bağımlılığ1 tanı kriterlerini kullandığ1 araştırma, bu alanda yapılan birçok çalışmada alıntılanan en temel kaynaktır (Akt. Chou ve Hsiao, 2000).

İnternet Bağımlıllğı Bozukluğu çeşitli davranışsal ve dürtü-kontrol problemlerini kapsayan geniş boyutlu bir kavramdir (Soule, Shell ve Kleen, 2003). Bunlar;

1. Sanal cinsel bağımlılık - yetişkin sohbet odası veya sanal porno bağımlılığı

2. Sanal İlişki bağımlılı̆̆ı - sohbet odalanında veya sanal porno sitelerinde çevrimiçi arkadaşliklar edinme

3. Kontrol edilemeyen internet ağı kullanımı - kumar oynama, ticaret yapma, açık artırma alışveriş yapma

4. Aşırı bilgi toplama davranışı - gereğinden fazla web veya veri tabanlarında gezinme

5. Bilgisayar bağımlılığ1 - kontrol edilemeyen oyun oynama veya programlama

Young'a (1996) göre internet bağımlllı̆̆ı, sarhoş edici içermeyen bir dürtü-kontrol bozukluğudur (Akt, Young, 2004: 404). Kandell (1998) ise internet bağımlılı̆̆ını, oturum açmış olduğu faaliyet türüne bakılmaksızın İnternete psikolojik bir bağlılık olarak tanımlamıştır (Akt, Kandell, 2009). Young (1996), davranıssal bir bozukluk olarak kabul edilen patolojik kumar oynama tanı kriterlerini, patolojik İnternet bağımlılığına uyarlamış ve sekiz maddelik bir internet bağımlılı̆̆1 tanı ölçütü geliştirmiştir (Akt, Young, 1998). Maddelerin beşine veya daha fazlasına "evet" cevabını veren katılımcılar, bağımlı Internet kullanıcıları (Bağımlılar) ve geri kalanlar normal Internet kullanıcıları (Bağımlı Olmayanlar) olarak değerlendirilmektedir. İnternet bağımlılığ1 kriterlerine ilişkin maddeler aşağıda verildiği şekildedir.

1. Sürekli interneti düşünür müsünüz? (sürekli olarak önceki ve daha sonra yapacağ1 çevrimiçi etkinlikleri düşünme) 
Aycan, A. \& Üzüm, H. (2020). Spora katılımın lise öğrencilerinin internet bağımlilı̆̆ına etkisi. Journal of Human Sciences, 17(4), 1022-1033. doi:10.14687/jhs.v17i4.6051

2. Daha fazla keyif almak için sürekli artan oranda internet kullanma ihtiyacı duyar mısınız?

3. İnternet kullanımını kontrol etmek, azaltmak veya durdurmak için sürekli olarak başarısız çabalar gösterdiniz mi?

4. İnternet kullanımının azaltılması ya da tamamen kesilmesi için çabaladığınızda huzursuz, karamsar, depresif veya asabi hissediyor musunuz?

5. Planladığınızdan daha uzun süre çevrimiçi kalıyor musunuz?

6. İnternet kullanımı nedeniyle ilişki, iş, eğitim veya kariyer fırsatını tehlikeye attınız mı?

7. İnternet ile uğraşma derecenizi gizlemek için aile üyelerine, terapistlere veya diğerlerine yalan söylediniz mi?

8. İnterneti problemlerden kaçmak ya da depresif bir ruh halini (örneğin çaresizlik, suçluluk, endişe, depresyon gibi) hafifletmenin bir yolu olarak mı kullanıyorsunuz?

Griffiths'e (1998) göre internet bağımlılı̆̆ını, davranışsal bağımlılıkların alt grubunda (zorunlu kumar gibi) yer alan bir tür teknolojik bağımlllk ( bilgisayar bağımlılı̆̆ı gibi) ve internetin aşırı kullanımının bazı bireyler için gerçek bir bağımllık ve gerçek bir endişe kaynağı olduğunu belirtmiştir (Akt, Chou, 2005). Griffiths'e (1998) göre aşağıdaki kriterleri karşılayan herhangi bir davranış bağımlılık olarak tanımlanmıştır (Akt, Chou, 2000).

1. Belirginlik: İnternet kullanımı gibi belirli bir etkinlik, öznenin hayatındaki en önemli etkinlik haline gelmesi ve düşüncesine hükmetmesi

2. Ruh hali değişikliği: Belirli bir faaliyete katılmanın sonucunda elde edilen kişisel deneyimler

3. Bağış1klık geliştirme: Arzu edilen etkilerin elde edilmesi için belirli bir aktivite veya zamanın artan miktarlarının gerekli olması

4. Yoksunluk belirtileri: Belirli bir aktivite durduğunda veya kısıtlandığında hoş olmayan duyguların veya fiziksel etkilerin görülmesi

5. Çatışma: Bağımlıların kendi arasında, bağımlılar ve etraflarındakiler arasında, bağımlıların kendileriyle ve yaşamlarındaki diğer faaliyetlerle olan çatışma/çekişme

6. Nüksetmek: Bağımlılık yapıcı aktivitenin tekrar oluşması eğilimi

Aşırı İnternet kullanımı bireyleri sosyal ilişkilerinde yabancılaştırmakta ve hatta yaşamlarında baskın sosyal faktör olarak yer alabilmektedir (Amichai - Hamburger, 2003). Özellikle internetin üniversite kampüslerinde kullanımının çarpıcı bir şekilde artması (bilgisayar laboratuvarları, yurtlarda sağlanan internet imkanı ve mobil Internet cihazları), üniversite öğrencilerinde görülen internet bağımlılı̆̆ının en önemli nedeni olarak görülmektedir (Young, 2004; Kendall, 2009). Young'a (2004) göre üniversite kampüslerinde internetin kötüye kullanımına katkıda bulunan etkenler yedi başlık altında toplanabilir. Bunlar;

1. Ücretsiz ve sınırsız İnternet erişimi

2. Akademik faaliyet dışı zamanın fazla olması

3. Ebeveyn kontrolünden uzakta, özgür bir yaşam

4. Çevrimiçi yaptıklarının ve söylediklerinin izlenmemesi ve sansürlenmemesi

5. İnternet kullanımı konusunda, fakülte ve okul idarecilerin tam teşviki

6. Sosyal baskı ve yabancılaşma

7. Yasal içki içme yaşının yüksek olması

Internet, internet tabanlı uygulamalar ve internete bağlanmayı sağlayan cihazlar hayatın vazgeçilmez ve gerekli araçları haline geldiği günümüzde internetin patolojik kullanımı yeni bir bağımlılık türü olarak nitelenebilecek internet bağımlılı̆̆ına yol açmaya başlamıştır. Kontrolsüz internet kullanımı bireylerin fiziksel, psikolojik, sosyal, bilişsel sağlığını ve yaşamını olumsuz yönde etkilemektedir (Bozkurt, 2016).

İnternet bağımlılığının tedavisi ile ilgili kesin tedavi yöntemleri olmasa da, farmakoterapi ve psikoterapi yöntemleri bu amaçla kullanılmaktadır (Bozkurt, 2016). 
Aycan, A. \& Üzüm, H. (2020). Spora katılımın lise öğrencilerinin internet bağımlilı̆̆ına etkisi. Journal of Human Sciences, 17(4), 1022-1033. doi:10.14687/jhs.v17i4.6051

Genel anlamda internet bağımlılığı tespiti ve tedavisi zor olan oldukça karmaşık bir konudur. Bu durum, normal internet kullanımı ve patolojik internet kullanımın ayrımı çok iyi yapılmamasını gerekli kılmaktadır (Young, 2004). Teknolojik gelişmelerden de sonuna kadar faydalanması için her türlü imkanın sağlanması gereken gençlerin aynı zamanda onun zararlarından korumak ve kontrollü kullanımını sağlamak oldukça önemli bir konudur. Örgün eğitim öğrencisi olan gençlerin internet ve diğer bütün bağımlılıklardan korunması okul, aile ve öğrenci işbirliğini gerektirmektedir (Arslan, ve diğ., 2015; Erden ve Hatun, 2015; İlhan ve diğ., 2014).

Gençlerin teknoloji ile bağımlılıktan uzak ve sağlıklı bir ilişki kurmaları için öncelikli olarak teknoloji bağımlllğına sebep olan faktörleri ortadan kaldırmak gerekmektedir. Bu da gençlerin enerjilerini sağlıklı bir şekilde boşaltabilecekleri, kendilerini gösterebilecekleri ve ifade edebilecekleri, akranlarıyla sosyalleşebilecekleri zeminlerin ve imkânların varllğıyla mümkündür (Dinç, 2005). Bu imkanı sağlamada spor, bireylerin fiziksel, ruhsal ve sosyal yönden gelişmesine olan katkılarıyla en etkili araçlardan biri olabilir (Hassmen, 2000; Warburton, 2006).

Park ve diğ., (2016) Güney Koreli ortaokul ve lise çağındaki öğrencileri ile gerçekleştirmiş oldukları çalışmada, spora katılım, kendilik kontrolü ve internet bağımlılığı arasındaki ilişkiyi incelemişlerdir. Araştırma sonucuna göre, spora katılımın kendilik kontrolü aracillğıyla internet bağımlılı̆̆1 üzerinde önemli bir etkisinin olduğunu ve sporun birçok bağımlılığının tedavisinde kullanılabileceğini belirtmişlerdir. Ayrıca, sporun ve fiziksel aktivitenin birçok faydalarının olduğunu (fiziksel ve psikolojik) ve ergenlerin gelişiminde karşılaşılan çeşitli sorunların çözümünde de kullanılması gerektiğini vurgulamışlardır.

Şenışık ve Hastürk'ün (2011) ergenlerde düzenli egzersizin internet kullanımıyla ilişkisini araştırdıkları çalısmada, düzenli egzersiz yapan grubun yapmayanlara göre internet kullanım süreleri daha az olmasına rağmen her iki grup arasında istatistiksel olarak anlamlı bir farkın olmadığını belirtmişlerdir. Araştırmacılar, okuldaki akademik birçok konunun ve günlük iletişimin internet aracılı̆̆ıyla yapılıyor olmasını bu sonucun nedeni olarak göstermişlerdir.

Hazar ve dĭğ., (2017) yapmış oldukları çalışmada, düzenli olarak spor yapmayan ortaokul öğrencilerinin dijital oyun bağımllıklarının spor yapan öğrencilerden anlamlı düzeyde yüksek olduğu sonucuna ulaşmışlardır. Teknolojik oyun araçlarını kullanma eğiliminin artmasının ve bundan dolayı fiziksel aktivite gerektiren oyunlardan uzaklaşılmasının bu sonucun nedeni olabileceğini belirtmişlerdir.

Internete telefonla bağlanmanın sağladığı kolaylıklar neticesinde internet bağımlılı̆̆ına olan eğilimi arttırması (Derin, 2013) ve kendine ait cep telefonu bulunan ve cep telefonunda internet bağlantısı olan ortaokul öğrencilerin internet bağımlılık puanlarının daha yüksek bulunması (Kısa, 2018) cep telefonunun internet bağl1lı̆̆1 oluşmasında etkili olabileceğini düşündürmektedir.

Kwon ve dĭ̆., (2013) göre internet tabanlı akıllı araçların toplumda çı̆̆ır açan değişiklere neden olmasına rağmen, akıllı telefon bağımlılığı ile ilgili yeteri kadar çalışmanın yapılmadığını belirtmişlerdir. Ayrıca, lise öğrencilerin lisansüstü öğrencilere göre akıllı telefon bağımllıklarının anlamlı düzeyde yüksek olduğunu tespit etmişlerdir.

Liu ve diğ., (2019) akıllı telefon bağımlılı̆̆ını tedavi etmede egzersizin yerini inceledikleri çalışmada, egzersizin akıllı telefon bağımlılı̆̆ı olan bireyler arasında bağımlılık düzeyini azaltmada iyileştirici etkilere sahip olduğunu vurgulamışlardır.

\subsection{Araştırmanın Amacı}

Bu çalışmada, lise öğrencilerinin spor yapma durumlarının internet bağımlılık düzeyine etkisin belirlenmesi amaçlanmıştır. Bu amaca ulaşmak için, lisanslı olarak spor yapan ve lisanlı olarak spor yapmayan öğrenciler bazı kişisel özelliklerine göre (cinsiyet, spor yapma durumu, not ortalaması ve cep telefonu kullanım yılı) internet bağımlılık düzeyleri karşılaştırılmıştır.

\subsection{Araştırmanın Önemi}

Spor ve internet bağımlılı̆̆ arasındaki ilişkiyi ortaya koymaya çalışan araştırmaların sayısı ve niteliğinin artması, internet ve internet ile ilgili araçların zararlı etkileriyle baş edilmesinde spordan çok daha fazla yararlanılmasının yolunu açabilir. Spora katılımın diğer bağımlılıklarda olduğu gibi internet bağımlılı̆̆ tedavi programlarında da kullanılabilecek etkili ve gerekli bir araç olmasının 
Aycan, A. \& Üzüm, H. (2020). Spora katılımın lise öğrencilerinin internet bağımlllı̆̆ına etkisi. Journal of Human Sciences, 17(4), 1022-1033. doi:10.14687/jhs.v17i4.6051

yanında, farmakolojik tedavinin aksine birçok psikolojik ve fiziksel faydaları söz konusudur (Park vd., 2016). Yakın zamanda çok daha fazla duyacağımız ve etkisini hissedeceğimiz internet bağımlılığ1 konusunda yapılacak her türlü çalışma konunun her yönüyle anlaşılmasına katkı sağlayarak, internetin olumsuz yanlarından korunmamıza yardımcı olabilir.

\section{1. Çalışmanın Modeli}

\section{Yöntem}

Araştırma amacı doğrultusunda genel tarama modellerinden biri olan ilişkisel tarama modeline göre yapilmıştır.

\section{2. Çalı̧̧ma Gurubu}

Araştırmanın çalışmanın evreni aynı zamanda örneklem grubunu oluşturmuştur. Oransız eleman örnekleme yöntemi ile seçilen örneklem grubu Bolu merkezindeki 10 farklı liselerde okuyan 215 erkek ve 215 kadın olmak üzere toplam 430 öğrenciden (220 lisanlı spor yapan ve 210 lisanslı olarak spor yapmayan) oluşmuştur.

\subsection{Veri Toplama Arac1}

Çalışmada veri toplama aracı olarak Kutlu ve diğ., (2016) tarafindan Türkçeye uyarlanan "Young İnternet Bă̆ımlilĭğ Testi Kısa Formu” (YIBT-KF) kullanılmıştır. 12 maddeden oluşan ölçeğin Cronbach Alpha iç tutarlılık değerleri $\alpha=0.70$ 'dir. Bu çalışma için, ölçeğin Cronbach Alpha iç tutarlılık değerleri ise $\alpha=0.93$ olarak hesaplanmıştır. 5 kategori üzerinden değerlendirilen maddelerin sayısal olarak karşılığ1; Hiçbir zaman=1, Nadiren=2, Ara sıra=3, Sık Sik=4, Her zaman $=5$ olacak şekilde puanlanmıştır. Veriler yüz yüze görüşme yöntemi kullanılarak toplanmıştır.

\subsection{Verilerin Analizi}

Araştırma kapsamında toplanan verilerin analizi için öncelikle normallik sınamasında Skewness ve Kurtosis değerlerinin (+2 ile -2) arasında olduğu dikkate alınarak grupların normal dağ 1 llım gösterdiği tespit edilmiştir $\mathrm{P}>0,05$. Dolayısıyla çalışmada parametrik hipotez testlerinin kullanılmasına karar verilmiştir. Bu doğrultuda katılımcıların demografik verilerinin dağılımının belirlenmesi için yüzde (\%) ve frekans (f) analizleri, iki grubun karşılaştırılması için T-testi ve sürekli sayısal veriler için Pearson Korelasyon testleri uygulanmıştır. Çalışmanın anlamlılık düzeyi $\mathrm{p}<0,05$ olarak kabul edilmiştir.

\subsection{Araştırmanın Etik İzinleri}

Yapılan bu çalışmada "Yükseköğretim Kurumları Bilimsel Araştırma ve Yayın Etiği Yönergesi” kapsamında uyulması belirtilen tüm kurallara uyulmuştur. Yönergenin ikinci bölümü olan "Bilimsel Araştırma ve Yayın Etiğine Aykırı Eylemler" başlı̆̆ı altında belirtilen eylemlerden hiçbiri gerçekleştirilmemiştir.

\section{Etik kurul izin bilgileri}

Etik değerlendirmeyi yapan kurul adı = Bolu Abant İzzet Baysal Üniversitesi / Sosyal Bilimlerde İnsan Araştırmaları Etik Kurulu

Etik değerlendirme kararının tarihi $=03.05 .2019$

Etik değerlendirme belgesi sayı numarası $=2019 / 213$

\section{Bulgular}

Katılımcıların cinsiyet ve lisanslı olarak spor yapıp yapmama durumlarına ilişkin özellikleri Tablo 1'de verilmiştir.

Tablo 1. Katılımcıların Özellikleri

\begin{tabular}{llccc}
\hline & & f & \% & Toplam \\
\hline \multirow{2}{*}{ Cinsiyet } & Erkek & 215 & 50,0 & 430 \\
& Kadin & 215 & 50,0 & 430 \\
\hline \multirow{2}{*}{ Lisanslı Sporcu } & Evet & 220 & 51,2 & 430 \\
& Haylr & 210 & 48,8 & 430 \\
\hline
\end{tabular}


Aycan, A. \& Üzüm, H. (2020). Spora katılımın lise öğrencilerinin internet bağımlılı̆̆ına etkisi. Journal of Human Sciences, 17(4), 1022-1033. doi:10.14687/ihs.v17i4.6051

Lisanslı spor yapan ve yapmayan katılımcıların internet bağımlılı̆̆ının karşılaştırılması ile ilgili bulgular Tablo 2'da verilmiştir.

Tablo 2. Lisanslı Spor Yapan ve Yapmayan Katılımcıların İnternet Bağımlığının Karşılaştırılması

\begin{tabular}{|c|c|c|c|c|c|c|}
\hline & & $\mathbf{n}$ & $\bar{x}$ & S & $\mathbf{t}$ & $\mathrm{p}$ \\
\hline İnternet & Lisanslı Spor Yapan & 220 & 2,00 & 0,90 & \multirow{2}{*}{$-10,40$} & \multirow{2}{*}{0,00} \\
\hline Bağımlılığ1 & Spor Yapmayan & 210 & 3,00 & 1,08 & & \\
\hline
\end{tabular}

$\mathrm{P}<0,05$

Tablo 2 incelendiğinde, lisanslı spor yapan katılımcılar ile yapmayan kattlımcılar arasında spor yapmayanlar lehine internet bağımlllğı puanı arasında istatistiksel olarak anlamlı farklılık bulunmuştur $\mathrm{P}<0,05$.

Lisanslı spor yapan katılımcıların internet bağımlılıklarının cinsiyet değişkenine göre karşılaştırılması ile ilgili bulgular Tablo 3'de verilmiştir.

Tablo 3.Lisanslı Olarak Spor Yapanların Cinsiyete Göre Karşılaştırılması

\begin{tabular}{llccccc}
\hline & Cinsiyet & $\mathbf{n}$ & $\mathbf{x}$ & $\mathbf{S}$ & $\mathbf{t}$ & P \\
\hline \multirow{2}{*}{ Lisanslı Spor Yapan } & Erkek & 123 & 2,06 & 0,86 & \multirow{2}{*}{1,10} & \multirow{2}{*}{0,26} \\
& Kadın & 97 & 1,92 & 0,95 & & \\
\hline
\end{tabular}

$\mathrm{P}>0,05$

Tablo 3 incelendiğinde, lisanslı spor yapan katılımcıların cinsiyeti ile internet bağımlılıkları arasında istatistiksel olarak anlamlı bir fark bulunmamıştır $\mathrm{P}>0,05$.

Spor yapmayan katılımcıların internet bağımlilıklarının cinsiyet değişkenine göre karşılaştırılması ile ilgili bulgular Tablo 4'de verilmiştir.

Tablo 4. Spor Yapmayanların Cinsiyete Göre Karşılaştırılması

\begin{tabular}{llccccc}
\hline & Cinsiyet & $\mathbf{n}$ & $\mathbf{x}$ & $\mathbf{S}$ & $\mathbf{t}$ & $\mathbf{p}$ \\
\hline \multirow{2}{*}{ Spor Yapmayan } & Erkek & 92 & 3,01 & 1,13 & \multirow{2}{*}{0,21} & \multirow{2}{*}{0,83} \\
& Kadın & 118 & 2,98 & 1,04 & & \\
\hline
\end{tabular}

$\mathrm{P}>0,05$

Tablo 4 incelendiğinde, spor yapmayan katılımcıların cinsiyeti ile internet bağımllıkları arasında istatistiksel olarak anlamlı bir fark tespit edilmemiştir $\mathrm{P}>0,05$.

Lisanslı spor yapan ve spor yapmayan katılımcıların not ortalaması ile internet bağımliliğ1 arasındaki ilişki gösteren bulgular Tablo 5'de verilmiştir.

Tablo 5. Lisanslı Spor Yapan ve Yapmayan Katılımcıların Not Ortalaması ile İnternet Bağımlı̆̆1

\begin{tabular}{lcc}
\multicolumn{3}{c}{ Arasındaki İlişki } \\
\hline \multirow{2}{*}{ Lisanslı Spor Yapan } & $\mathrm{r}$ & İnternet Bağımlılı̆̆1 \\
\hline \multirow{2}{*}{ Spor Yapmayan } & $\mathrm{p}$ & $-0,31 * *$ \\
& $\mathrm{r}$ & 0,00 \\
\hline
\end{tabular}

$* \mathrm{P}<0,05$ 
Aycan, A. \& Üzüm, H. (2020). Spora katılımın lise öğrencilerinin internet bağımlilı̆̆ına etkisi. Journal of Human Sciences, 17(4), 1022-1033. doi:10.14687/ihs.v17i4.6051

Tablo 5 incelendiğinde; lisanslı spor yapan katılımcıların not ortalaması ile internet bağımlılıkları arasında negatif yönde düşük düzeyde $(\mathrm{r}=-0,31)$ anlamlı bir ilişki saptanmıştır $\mathrm{P}<0,05$. Spor yapmayan katılımcıların not ortalaması ile internet bağımlılıkları arasında anlamlı $(\mathrm{r}=-0,08)$ bir ilişki bulunmamaktadır $\mathrm{P}>0,05$.

Lisanslı spor yapan ve spor yapmayan katılımciların cep telefonu kullanım yll ile internet bağımlilı̆̆1 arasındaki ilişki Tablo 6'de verilmiştir.

Tablo 6. Lisanslı Spor Yapan ve Yapmayan Katılımcıların Cep Telefonu Kullanım Yılı İle İnternet Bağımlığı Arasındaki İlişski

\begin{tabular}{lcc}
\hline & & Internet Bağımlılı̆̆1 \\
\hline \multirow{2}{*}{ Lisanslı Spor Yapan } & $\mathrm{r}$ & $-0,30^{* *}$ \\
\hline \multirow{2}{*}{ Spor Yapmayan } & $\mathrm{p}$ & 0,00 \\
\hline
\end{tabular}

$* \mathrm{P}<0,05$

Tablo 6 incelendiğinde; lisanslı spor yapan katılımcıların cep telefonu kullanım yllı ile internet bağımlılıkları arasında negatif yönde düşük düzeyde $(\mathrm{r}=-0,30)$ anlamlı bir ilişki bulunmuştur. Ayrıca, spor yapmayan katılımcıların cep telefonu kullanma yllı ile internet bağımlilıkları arasında pozitif yönde düşük düzeyde anlamlı $(\mathrm{r}=0,32)$ bir ilişki görülmektedir $\mathrm{P}<0,05$.

\section{Sonuç ve Öneriler}

Lise öğrencilerinin spor yapma durumlarına göre internet bağımlılık düzeylerinin belirlenmesinin amaçlandığı bu çalışmanın bulguları, öğrencilerin cinsiyet, not ortalaması, cep telefonu sahiplik süresi ve lisanslı olarak spor yapıp yapmama durumları incelenerek elde edilmiştir.

Araştırmada, lisanslı spor yapan grup ile spor yapmayan grubun internet bağımlılık düzeyleri karşılaştırıldığında da, spor yapan grubun internet bağımlılık düzeyinin yapmayan gruptan istatistiksel olarak anlamlı düzeyde daha düşük olduğu sonucuna varılmıştır (Tablo 2). Ortaokul ve lise çağındaki ergenlerin katılımıyla gerçekleştirilen bazı araştırmalarda, düzenli egzersizin internet bağımlılı̆̆ını azaltmadaki etkisini kendilik kontrolü sağlayarak ve bireyleri sanal ortamdan uzaklaştırıp daha çok gerçek hayatın içinde tutarak gösterdiği sonucuna ulaşılmıstır (Hazar ve diğ., 2017; Park ve diğ., 2016; Şenışı ve Hastürk, 2011).

Araştırmada, spor yapan ve yapmayan grubun kendi içinde cinsiyetleri bakımından internet bağımlılık düzeyleri arasında anlamlı bir farklılık tespit edilmemesine rağmen, her iki grupta da erkeklerin da daha yüksek bağımlılığa sahip oldukları bulgusuna ulaşılmıştır (Tablo 3,4). Erkek öğrencilerinin internet bağımlılık düzeylerinin daha yüksek bulunduğu bazı araştırmalarda, erkeklerin internete ve internet erişim olanaklarına toplumsal cinsiyet rollerinin etkisiyle daha fazla sahip olmaları bu sonucun nedeni olarak gösterilmektedir (Arslan ve diğ., 2015; Derin, 2013; Esen ve Siyez, 2011; Hazar ve diğ., 2017; İlhan ve diğ., 2014; Yılmaz, Şahin, ve diğ., 2014).

Araştırmanın bir diğer bulgusu, spor yapan öğrencilerin internet bağımlılıklar ile akademik başarıları (not ortalamaları) arasında negatif yönlü anlamlı bir ilişkinin olduğu, spor yapmayan öğrencilerde ise internet bağımlılı̆̆1 ve akademik başarı arasında anlamlı bir ilişkinin olmadığ1 yönündedir (Tablo 5). Araştırma sonucuna göre, özellikle spor yapan öğrencilerde akademik başarılarının düşmesinin internet bağımlılıklarını veya internet bağımlılıklarının artmasının akademik başarılarının düşmesine spor yapmayanlara göre daha fazla neden olabileceği göz ardı edilmemelidir. Buna rağmen, diğer araştırma sonuçları da dikkate alındığında, lise öğrencilerinde internet kullanımının bütün öğrencilerde akademik başarısızlığa yol açabileceği sonucuna ulaşılabilir. 
Aycan, A. \& Üzüm, H. (2020). Spora katılımın lise öğrencilerinin internet bağımlılı̆̆ına etkisi. Journal of Human Sciences, 17(4), 1022-1033. doi:10.14687/ihs.v17i4.6051

Ortaokul ve lise öğrencilerinde (ergenlerde) internet bağımlılı̆̆ ve akademik başarı arasındaki ilişkinin değerlendirildiği bazı çalışmalarda, düşük eğitim seviyesi ile düşük akademik başarının yüksek internet bağımlığına (Esen ve Siyez, 2011; Yıldız, ve dĭg., 2018), aşırı eğlence amaçlı internet kullanımının akademik başarısızlı̆ga (Kısa, 2018) ve okul başarısının internet bağımlılı̆̆ında azalmaya (Akgül, 2016) ve neden olduğu sonucuna varılmıştır.

Araştırmada, spor yapan ögrencilerin cep telefonu kullanım y1l ile internet bağımlılıklanı arasında negatif yönde, spor yapmayan katılımciların cep telefonu kullanma y1lı ile internet bağımlilıkları arasında pozitif yönde anlamlı bir ilişki olduğu görülmektedir (Tablo 6). Başka bir değişle, spor yapanların cep telefonu sahiplik süresi arttıkça internet bağımlılıkları azalmakta, spor yapmayanlarda ise artmaktadır. $\mathrm{Bu}$ sonuç, spor yapanların internet bağımlilıklarının yapmayanlardan daha düşük bulunduğu (Tablo 2) verilerle de örtüşmektedir.

Internet tabanlı akıllı araçların toplumda çığır açan değişiklere neden olmakta (Kwon ve dĭ̆., 2013), ve akıllı telefon kullanım süresinin fiziksel kapasiteyi olumsuz yönde etkilemektedir (Erdanoğlu ve Arslan, 2019). Akıllı telefon bağımlılı̆̆ı olan kişilerin akıllı telefonlarını ile daha fazla zaman geçirmelerinden dolayı, fiziksel olarak hareketsiz kalmalarına ve bu durumun ise kas kütlesini azaltmaya ve yağ kütlesini artırmaya neden olabilmektedir (Kim, ve diğ., 2015). Yapilan bazı araştırmalarda, lise öğrencileri arasında akıllı telefon kullanımının oldukça yoğun olduğu, akıllı telefon bağımlılı̆ğ ile yalnızlık duygusu arasında pozitif yönlü anlamlı bir ilişkinin bulunduğu ve telefon kullanım süresi arttıkça yalnızlık sorunun azaldığı belirtilmiştir (Çakır ve Oğuz, 2017; Şar, 2013). Bu sonuçlardan, akıllı telefon kullanımı yalnızlığın hem bir nedeni hem de bir sonucu olarak görülebilir. Liu ve diğ., (2019) göre, akıllı telefon bağımlılığını tedavi etmede egzersiz iyileştirici etkilere sahiptir. Bu bulgular ışığında, spor yapmanın fiziksel ve psikolojik faydalarının yanında sosyal faydalarının da cep telefonundan kaynaklanabilecek bağımlılı̆̆ önlemede oldukça etkili bir araç olabileceği şeklinde yorumlanabilir.

Araştırmada, a) spor yapan öğrencilerin internet bağımlılıklarının yapmayanlardan daha düşük olduğu, b) erkek öğrencilerin internet bağımllık düzeylerinin kadın öğrencilerden daha yüksek olduğu, c) spor yapanlarda yapmayanlara göre akademik başarının internet bağımlılı̆̆ında daha etkili olduğu ve d) spor yapanlarda yapmayanlara göre cep telefonu kullanım yılının internet bağımlllı̆̆ına etkisinin daha az olduğu sonucuna ulaşılmıştır.

\section{Kaynakça}

Akgül, B. M. (2016). The reflections of smartphone use and recreational use of internet by high school students to leisure boredom and academic achievement. European Journal of Physical Education and Sport Science, 2(5),1-20.

Amichai-Hamburger, Y., \& Ben-Artzi, E. (2003). Loneliness and internet use. Computers in Human Behavior, 19(1), 71-80.

Arısoy, Ö. (2009). İnternet bağımlılığ1 ve tedavisi. Psikiyatride Güncel Yaklaşımlar, 1(1), 55-67.

Arslan, A., Kırık, A. M., Karaman, M., ve Çetinkaya, A. (2015). Lise ve üniversite öğrencilerinde dijital bağımllık. Uluslararası Hakemli İletişim ve Edebiyat Araştırmaları Dergisi, 8(8), 3458. Doi: 10.17361/UHIVE.2015813153.

Balc1, Ş., ve Gülnar, B. (2009). Üniversite öğrencileri arasında internet bağımlıllğ̆1 ve internet bağımlılarının profili. Selçuk Üniversitesi İletişim Fakültesi Akademik Dergisi, 6(1), 5-22.

Bozkurt, H., Şahin, S., ve Zoroğlu, S. (2016). İnternet bağımlllı̆ı: güncel bir gözden geçirme. Journal of Contemporary Medicine, 6(3), 235-247.

Cash, H., D Rae, C., H Steel, A., \& Winkler, A. (2012). Internet addiction: a brief summary of research and practice. Current Psychiatry Reviews, 8(4), 292-298.

Chou, C., \& Hsiao, M. C. (2000). Internet addiction, usage, gratification, and pleasure experience: the Taiwan college students' case. Computers and Education, 35(1), 65-80.

Chou, C., Condron, L., \& Belland, J. C. (2005). A review of the research on internet addiction. Educational Psychology Review, 17(4), 363-388. 
Aycan, A. \& Üzüm, H. (2020). Spora katılımın lise öğrencilerinin internet bağımlilı̆̆ına etkisi. Journal of Human Sciences, 17(4), 1022-1033. doi:10.14687/jhs.v17i4.6051

Çakır, F. ve Singın, R. H. Ö. (2019). Üniversite öğrencilerinde spora yönelik tutum ve internet bağımlılığı ilişkisinin incelenmesi. Sportif Bakış: Spor ve Eğitim Bilimleri Dergisi, 6(2), 163-178.

Çakır, Ö., ve Oğuz E. (2017). Lise öğrencilerinin yalnızlık düzeyleri ile akıllı telefon bağımlılığı arasındaki ilişki. Mersin Üniversitesi Eğitim Fakültesi Dergisi, 13(1), 418-429.

Derin, S. (2013). Lise öğrencilerinde internet bağımlılı̆̆1 ve öznel iyi oluş (Yayınlanmamış yüksek lisans tezi) Hacettepe Üniversitesi, Sosyal Bilimler Enstitüsü, Ankara.

Dinç, M. (2015). Teknoloji bağımlılı̆̆ı ve gençlik. Gençlik Araştırmaları Dergisi, 3(3), 31-65.

Erden, S., ve Hatun, O. (2015). İnternet bağımlılı̆̆ı ile başa çıkmada bilişsel davranışçı yaklaşımın kullanılması: bir olgu sunumu. Addicta: The Turkish Journal on Addictions, 2(1), 53-83.

Erdoğanoğlu, Y., ve Arslan, B. Ç. (2019). Gençlerde akıllı telefon kullanımının fiziksel kapasite üzerine etkisi. Anatolian Journal of Psychiatry/Anadolu Psikiyatri Dergisi, 20(5), 499-505.

Esen, E., ve Siyez D. M. (2011). Ergenlerde internet bağımlılı̆̆ını yordayan psiko-sosyal değişkenlerin incelenmesi. Türk Psikolojik Danışma ve Rehberlik Dergisi, 4 (36), 127-138.

Hassmen, P., Koivula, N., ve Uutela, A. (2000). Physical exercise and psychological well-being: a population study in Finland. Preventive Medicine, 30(1), 17-25.

Hazar, Z., Demir, G. T., Naml, S., ve Türkeli, A. (2017). Ortaokul öğrencilerinin dijital oyun bağımlılığı ve fiziksel aktivite düzeyleri arasındaki ilişkinin incelenmesi. Beden Eğitimi ve Spor Bilimleri Dergisi, 11(3), s. 320-332.

http://www.tuik.gov.tr/UstMenu.do?metod=temelist

İlhan, M., Dikmen, A., Uslu, İ., Medeni, V., Altun, B., ve Tezel , A. (2014). Ankara'da on beş yaş üstü kişilerin internet kullanımı sıklığ1 ve bağımlılı̆̆. Literatür Sempozyum, 34-42.

Kandell, J. J. (1998). Internet addiction on campus: the vulnerability of college students. Cyberpsychology and Behavior, 1(1), 11-17.

Kısa, Ö. (2018). Ortaokul öğrencilerinde yalnızlık ve sosyal beceri düzeyleri ile internet bağımlılı̆̆1 arasındaki ilişkinin incelenmesi (Yayınlanmamış yüksek lisans tezi) Kırklareli Üniversitesi, Sağlık Bilimleri Enstitüsü, Kütahya.

Kim, S. E., Kim, J. W., \& Jee, Y. S. (2015). Relationship between smartphone addiction and physical activity in Chinese international students in Korea. Journal of Behavioral Addictions, 4(3), 200-205.

Kutlu, M., Savc1, M., Demir, Y., ve Aysan, F. (2016). Young internet bağımlılığı testi kısa formunun Türkçe uyarlaması: üniversite öğrencileri ve ergenlerde geçerlilik ve güvenilirlik çalışması. Anadolu Psikiyatri Dergisi, 17(1), 69-76.

Kwon, M., Lee, J. Y., Won, W. Y., Park, J. W., Min, J. A., Hahn, C., ve diğer. (2013). Development and validation of a smartphone addiction scale (SAS). PloS one, 8(2), 1-7.

Liu, S., Xiao, T., Yang, L., \& Loprinzi, P. D. (2019). Exercise as an alternative approach for treating smartphone addiction: a systematic review and meta-analysis of random controlled trials. International Journal of Environmental Research and Public Health, 16(20), 3912.

Park, J. A., Park, M. H., Shin, J. H., Li, B., Rolfe, D. T., Yoo, J. Y., \& Dittmore, S. W. (2016). Effect of sports participation on internet addiction mediated by self-control: a case of Korean adolescents. Kasetsart Journal of Social Sciences, 37(3), 164-169.

Soule, L. C., Shell, L. W., \& Kleen, B. A. (2003). Exploring internet addiction: demographic characteristics and stereotypes of heavy internet users. Journal of Computer Information Systems, 44(1), 64-73.

Şar, A, H. (2013). Examination of loneliness and mobil phone addiction problem observed in teenagers from the some variables. The Journal of Academic Social Science Studies, 6 (2), 1207-1220.

Wang, H., Zhou, X., Lu, C., Wu, J., Deng, X., \& Hong, L. (2011). Problematic internet use in high school students in Guangdong province, China. PloS One, 6(5), e19660. 
Warburton, D. E., Nicol, C. W., \& Bredin, S. S. (2006). Health benefits of physical activity: the evidence. Cmaj, 174(6), 801-809.

Yıldız, K., Polat, E., ve Güzel, P. (2018). Espor oyuncularının internet bağımlılık düzeyleri ve oyun motivasyonları üzerine bir araştırma. 16. Uluslararası Spor Bilimleri Kongresi Tam Metin Kitab1, 31 Ekim-3 Kasım 2018, Antalya.

Yılmaz, E., Şahin, Y. L., Haseski, H. İ., ve Osman, E. (2014). Lise öğrencilerinin internet bağımlılık düzeylerinin çeşitli değişkenlere göre incelenmesi: Balıkesir ili örneği. Eğitim Bilimleri Araştırmaları Dergisi, 4(1), 33-144.

Young, K. S. (1998). Internet addiction: the emergence of a new clinical disorder. Cyberpsychology and Behavior, 1(3), 237-244.

Young, K. S. (2004). Internet addiction: a new clinical phenomenon and its consequences. American Behavioral Scientist, 48(4), 402-415.

\section{Extended English Summary}

\section{Introduction}

The Internet, which is an important part of daily life for many people is being used for communication, knowledge acquisition, purchasing and many more activities. In the recent years, the internet addiction as a new type of addiction has become an important field of study that draws attantion of researchers from various disciplines notably sociology, psychology and communication (Balc1 and Gülnar, 2009).

In every aspect of our lives (education, wellness, commerce, communication etc.), the number and importance of the activities that are being carried out by using the internet are increasing rapidly. This situation brings along the excessive, redundant and detrimental internet usage as well, and by affecting especially the youth and the children who have a better command at technology (Arisoy, 2009; Wang et. al 2011), induces them to face physical, mantal and social problems (Çakır and Singın, 2019; Dinç, 2015).

\section{Concept of Internet Addiction}

Goldberg is the first person to create a term to define the Internet Addiction Disorder (IAD) and to form a support group for Internet addicts in 1996. His research which he employed the diagnostic criteria of substance abuse to describe the Internet addiction disorder is the most common source that is being cited for a lot of studies in this field (Akt. Chou and Hsiao, 2000). Young (1996), adapted the diagnostic criteria of pathological gambling that is accepted as a behavioral disorder to pathological Internet addiction and developed an internet addiction diagnosis criteria with 8 items (Akt, Young, 1998). The participants who answer "yes" to 5 or more items are evaluated as addicted Internet users (Addicts) and the rest of the participants are evaluated as ordinary Internet users (Nonaddicts). The items regarding the criteria of Internet addiction are as stated below. Do you think of internet constantly? (continuously thinking about online activies that were performed previously and will be performed later).

1. Do you feel the need to use the internet on an ever-increasing rate to have more pleasure?

2. Did you make constant unsuccessful efforts to control, to reduce or to stop the internet usage?

3. Do you feel anxious, pessimistic, depressive or irritable when you struggle to reduce or completely disconnect the internet use?

4. Do you stay online for longer than you planned for?

5. Did you jeopardize the opportunities of relationship, job, education or career because of internet usage? 

17(4), 1022-1033. doi:10.14687/jhs.v17i4.6051

6. Did you lie to family members, therapists or others to conceal your degree of content with the internet?

7. Do you use the internet to run from the problems or as a way of easing a depressed mood (such as helplessness, guilt, anxiety, depression)?

Excessive Internet usage alienates individuals in their social relations and might even take part as a dominant social factor in their lives (Amichai-Hamburger, 2003). In this day and time when the internet, web based applications and the devices which ensure to connect the internet have become indispensable and essential tools of life, pathological use of internet has started to cause internet addiction which can be described as a new type of addiction. Unrestrained use of internet affects the individuals' physical, psychological, social, cognitive health and life in a negative way (Bozkurt,2016).

Protecting the youth who are students of formal education from internet and all other addictions require the cooperation of school, family and student (Arslan, Kirik, Karaman and Çetinkaya, 2015; Erden and Hatun, 2015; Illhan et. al, 2014). And this is possible with the existence of grounds and opportunities where the youth can healthfully spend their energies, manifest and express themselves, socialize with their peers (Dinç, 2005). To provide this opportunity, sports can be one of the most efficient tools with it's contributions to individuals' physical, mental and social development (Hassmen, 2000; Warburton, 2006).

Increase in the number and the quality of the studies -which aim to reveal the correlation between the sports and the internet addiction- can pave the way for benefiting a lot more from the sports to cope with the detrimental effects of the internet and the regarding tools. Along with being a potent and essential instrument that can be used in internet addiction treatment programs as being for other addictions,it is discussed that there are many psyhcological and physical benefits of participation in sports unlike pharmacological treatment (Park et. al, 2016). It is clear that all kinds of studies on the subject of internet addiction which we will be hearing about and feel the impacts of a lot more in the near future will help to avoid the adverse effects of internet by contributing to understanding the respected subject in every aspect. In this study, it was aimed to determine the effects of high school students' case of participating in sports on their internet addiction levels. To reach this goal, internet addiction levels of students who are certified athletes and who are not certified athletes are compared according to some personal characteristics (gender, state of exercising sports, grade-point average and the years of mobile phone usage).

\section{Method}

In accordance with the purpose, the research was conducted pursuant to sectioning approach which is one of the general survey models, and relational screening model. Population of the study also forms the sample group. The sample group which was choosen by simple random sampling method consist of 430 students as 215 male and 215 female (220 certified athlete and 210 non-certified) studying in 10 different high schools in Bolu city center. As data collecting tool for the study, "Young's Internet Addiction Test - Short Version" (YIAT-SV) which was adapted in Turkish by Kutlu, Savc1, Demir and Arslan (2016) was employed. Cronbach's Alpha internal consistency values of the scale that comprises of 12 items are $\alpha=0.70$. As for this study, Cronbach's Alpha internal consistency values were calculated as $\alpha=0.93$. Percentage (\%) and frequency ( $\mathrm{f}$ ) analysis to determine the distribution of participants' demographical data, T-Test to compare two groups, and Pearson's Correlation test for continuous numerical data were conducted. Significance level of the study was accepted as $\mathrm{p}<0,05$.

\section{Findings, Discussion and Results}


In the research, when the internet addiction levels of the group who are participating in sports as certified athletes and the group who are not participating in sports were compared, it was extrapolated that the internet addiction levels of the group exercising sports is lower by a statictically significant degree than the group that are not exercising sports (Table 2). In some researchs that were conducted with the participation of teenagers who are at the age of middle school and high school, it was concluded that exercising regularly shows it's effect on decreasing the internet addiction by providing self control and by keeping the individuals clear of virtual platforms and making them stay more in real life (Hazar et. al, 2017; Park et. al, 2016; Şenış1k and Hastürk, 2011).

In the study, even though there wasn't any significant distinctness confirmed between the internet addiction levels in recognition of genders within the groups that are exercising sports and not exercising sports themselves, it was founded in both groups that the males have higher addiction levels (Table 3,4). In some researchs which found the internet addiction levels of male students higher, males' having more opportunities for internet and internet access with the influence of the social gender roles is being shown as the cause of this result (Arslan et.al, 2015; Derin, 2013; Esen and Siyez, 2011; Hazar et.al, 2017; İlhan et.al, 2014; Y1lmaz, Şahin, Haseski and Osman., 2014).

Another finding of the study is that there is a significant avoidant relation between the internet addictions and academic success of the student's who participate in sports; and as for the students who don't participate in sports, there isn't a significant relation between the internet addiction and the academic success (Table 5). In certain studies which were evaluating the correlation between the internet addiction and academic success of middle school and high school studens (teenagers), it was deducted that low academic success causes high internet addiction (Esen ve Siyez, 2011), excessive use of entertainment targeted internet causes academic failure (Kısa, 2018: 74), and success at school causes decrease on the internet addiction (Akgül, 2016).

In the research, it is seen that there is a negatively oriented significant relation between the years of mobile phone usage and the internet addiction of the students who participate in sports and a positively oriented significant relation between the years of mobile phone usage and the internet addiction of the students who don't participate in sports (Table 6). Number of studies indicate that; mobile phone usage among high school students is quite intense, there is a positively oriented significant relation between the mobile phone addiction and loneliness feeling, and the matter of loneliness decreases as the duration of mobile phone usage increases (Çakır and Oğuz, 2017; Şar, 2013).

In the study, it was resulted a) internet addiction of the students who participate in sports are lower than the students who don't participate in sports, b) internet addiction levels of male students lower than female students, c) academic success is more effective on the internet addiction for the students who participate in sports compared to the students who don't participate in sports, and d) the year of mobile phone usage is less effective on the internet addiction for the students who participate in sports in comparison to the students who don't participate in sports. 